\title{
CURRENT APPLICATIONS OF SCANNING COHERENT DOPPLER LIDAR IN WIND ENERGY INDUSTRY
}

\author{
R Krishnamurthy ${ }^{1}$, M Boquet $^{1}$, E Osler $^{2 *}$ \\ ${ }^{1}$ LEOSPHERE SAS, 14 Rue Jean Rostand, 91400, France \\ ${ }^{2}$ Renewable NRG Systems, Vermont, USA, *Email: evan@rnrgsystems.com
}

\begin{abstract}
Scanning Doppler Lidars have become more prominent in the wind energy industry for a variety of applications. Scanning Lidar's provide spatial variation of winds and direction over a large area, which can be used to assess the spatial uncertainty of winds and analyze complex flows. Due to the recent growth in wind energy, wind farms are being built in complex terrain areas and fine tuning of the existing wind farms for optimized performance have gained significant interest. Scanning Lidar is an ideal tool for improved assessment of flow over complex terrains and wake characterization of large wind farms. In this article, the various applications of Lidar in the wind industry are discussed and results from several campaigns conducted in US and Europe is presented. The conglomeration of results provided in this article would assist wind energy developers and researchers in making improved decisions about their wind farm operations and pre-construction analysis using scanning Lidar's.
\end{abstract}

\section{EMERGING OPPORTUNITIES IN WIND ENERGY}

Wind energy is one of the leading contenders for providing clean renewable energy. In the United States, $35 \%$ of new installed power over the last five years was from wind energy (AWEA 2012). By the end of 2012, the U.S. had $60 \mathrm{GW}$ ( $\$ 120$ billion investment) of installed wind power. Because of this large and increasing national investment, cutting-edge developments in the remote sensing industry have gained significant interest to optimize the performance of existing and future wind farms. Traditionally, wind measurements have been carried out using meteorological towers which provide points measurements at hub heights. With the increase in rotor swept area and hub heights, the impact of wind shear and turbulence intensity on turbines become dominant and point measurements from meteorological towers are no longer a good representation of the wind interacting with the turbine [1]. In addition, wakes from large wind turbine designs have introduced several challenges in wind farm design. Remote sensing techniques - especially scanning coherent Doppler LIDAR (LIght Detection And Ranging), can bridge the gap by providing high-resolution velocity measurements in three-dimensional (3D) space.

The ability of scanning Lidar to produce data rich 3D measurements over a wind farm site helps improve our understanding of the fluid dynamical processes occurring over a wide range of scales. This leads to accurate characterization of wind turbine inflow parameters and allows better understanding different atmospheric conditions and wind events which influence wind power output. In addition, accurate measurements of the boundary layer at a wind farm site is required to properly characterize local boundary layer events such as the low-level jet, wind speed and direction shear, which are important for effective wind resource assessment. Coherent Doppler lidars have been used extensively for boundary layer studies [2], mountain meteorology [3, 4], wind resource assessment [5] and dispersion modeling [6]. This paper outlines the key results from various scanning Lidar deployments for wind energy applications. These results showcase the ability of the Lidar remote sensing platform to play a pivotal role in various aspects of wind farm design.

\section{CURRENT APPLICATION OF SCANNING LIDARS}

\subsection{ONSHORE WIND RESOURCE} ASSESSMENT

Accurate wind resource assessment requires spatial measurements of wind speed 
and direction at hub-height over the complete wind farm domain and the vertical structure over the turbine swept area. Wind farm resource assessment was carried out using 3D scanning lidar measurements performed at a wind development site in USA. The site-setup and initial results are shown below [7].

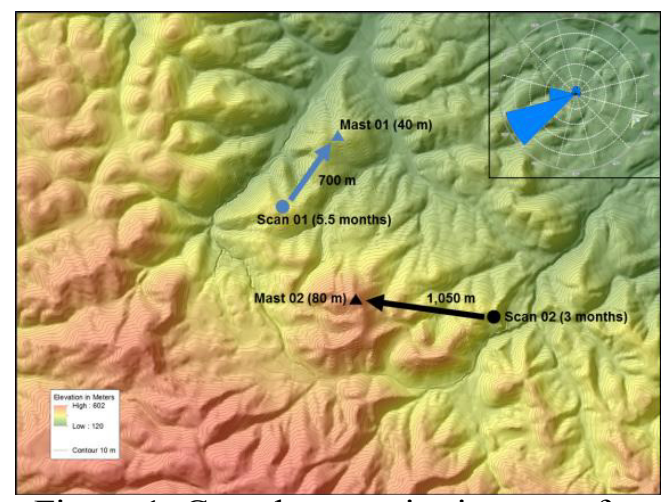

Figure 1. Complex terrain site setup for scanning Lidar site assessment.

The lidar measurements for several month were helpful in understanding the vertical and spatial structure of the wind field. Coherent Doppler lidar enables calculations of the wind speed distributions as a function of space and height which can be used to estimate the wind energy density for a given site.

Table 1. Wind speed correlation and bias comparison with tower measurements

\begin{tabular}{cccc}
\hline $\begin{array}{c}\text { Wind speed } \\
\text { at } 40 \mathrm{~m}\end{array}$ & Slope & $\mathbf{R}^{2}$ & Bias \\
\cline { 2 - 4 } & 0.99 & $94 \%$ & $-1.8 \%$ \\
& & & \\
\hline
\end{tabular}

\subsection{OFFSHORE WIND RESOURCE ASSESSMENT}

The relatively long range of the lidar and the wind farm location along the coast allows characterization of land-sea interactions. The ability of the Doppler lidar to make measurements over the sea surface provides a strategic advantage due to the prohibitive cost of setting up meteorological towers offshore (over \$1Million). Spatial variation of wind speed and direction were measured using a three-dimensional scanning Doppler lidar near a confidential coast in Europe. The analysis demonstrates the ability of the 3D scanning lidars to perform effective resource assessment for near-shore wind farms through measurement of the horizontal and vertical flow structure. Figure 2 prior onshore verification of the scanning Lidar being conducted in Germany by DNV GL. Initial results of the verification process are also shown in Table 2.

The results from the verification study conducted are shown in the tables below.

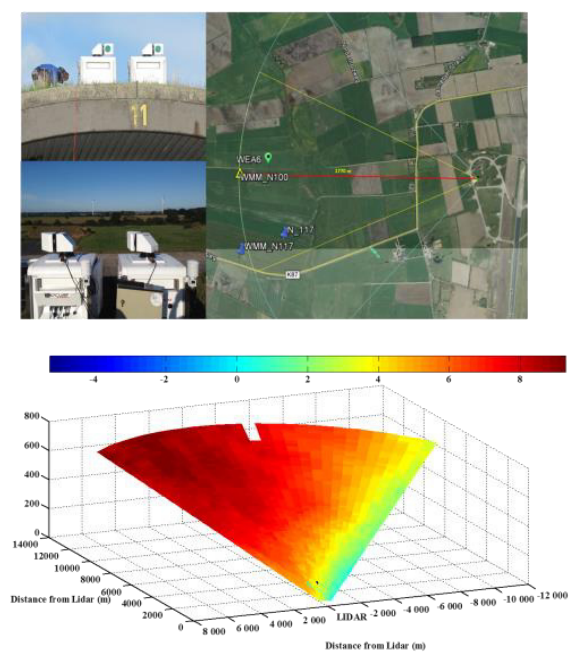

Figure 2. Site setup of the onsite verification of scanning Lidar by DNV GL.

\begin{tabular}{|c|c|c|c|c|}
\hline $\begin{array}{l}\text { U12 PLC4 - Wind } \\
\text { Direction } \\
\text { all WS }>3 \mathrm{~m} / \mathrm{s}\end{array}$ & Slope & \multicolumn{2}{|c|}{$\mathrm{R}^{2 * *}$} & $\begin{array}{l}\text { Mean WD } \\
\text { Difference }\end{array}$ \\
\hline (i) Along $\left(+/-45^{\circ}\right)$ & 0.999 & \multicolumn{2}{|c|}{0.995} & -2.742 \\
\hline (ii) Orthogonal $\left(+/-45^{\circ}\right)$ & 1.014 & \multicolumn{2}{|c|}{0.998} & -1.924 \\
\hline (iii) All directions & 1.003 & \multicolumn{2}{|c|}{0.998} & -2.325 \\
\hline $\begin{array}{l}\text { U12 PLC4 - Wind Speed } \\
\text { all }>2 \mathrm{~m} / \mathrm{s}\end{array}$ & $\begin{array}{l}\text { Mean } \\
\text { error } \\
/[\mathrm{m} / \mathrm{s}]\end{array}$ & $\begin{array}{l}\text { STD error } \\
/[\mathrm{m} / \mathrm{s}]\end{array}$ & Slope & $\mathrm{R}^{2 * *}$ \\
\hline (i) Along (+/- 45) & 0.24 & 0.32 & 0.991 & 0.976 \\
\hline (ii) Orthogonal $\left(+/-45^{\circ}\right)$ & 0.32 & 0.40 & 0.982 & 0.966 \\
\hline (iii) All directions & 0.28 & 0.36 & 0.986 & 0.971 \\
\hline
\end{tabular}

Table 2. Direction (top) and wind speed (bottom) comparison to tower measurements on site at $80 \mathrm{~m}$.

\subsection{WIND TURBINE/WIND FARM WAKE}

Large wind farms have been experiencing lower Annual Energy Production (AEP), due to lack of complete information of wind farm or wind turbine wakes. Scanning Lidar's provide 3D assessment of wakes and help fine tune the wind farm for optimal performance. Several 
campaigns have been conducted in offshore and onshore wind farms to assess the wake behavior. OWA (Offshore Wind Accelerator) is an industry funded program in the United Kingdom aiming to reduce the cost of offshore wind energy by $10 \%$. This project includes 4 major research areas, one of which is characterizing wake effects. Scanning Lidar's were used to:

1. Measure turbine inflow and outflow parameters

2. Validate advanced wake models

3. Characterize single turbine wakes

4. Characterize wind farm wakes

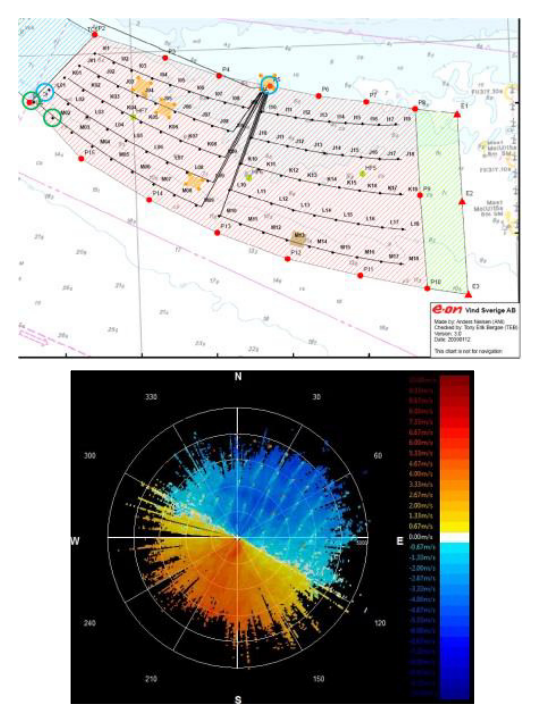

Figure 3. Site setup and measurements observed from scanning Lidar. Wind turbine wakes can be observed in the right figure.

\section{CONCLUSIONS}

Scanning Lidar's provide a new and attractive tool for wind energy applications. The frequent use of scanning Lidar's for wind energy applications for WRA, Power Curve and wake measurements have improve the AEP of wind farms. In this presentation, details on the impact of AEP for the above mentioned projects would be discussed.

\section{REFERENCES}

[1] Wagner et al., Rotor equivalent wind speed for power curve measurements, 2009, Journal of Physics Conference.

[2] Pichugina et al, Doppler Lidar-Based Wind-Profile Measurement System for Offshore Wind-Energy and Other Marine Boundary Layer Applications, 2010, Journal of Applied Meteorology and Climatology.

[3] Krishnamurthy et al., Wind Turbulence estimates in a complex terrain using Scanning Doppler lidar, 2011, Meteorological Applications

[4] Choukulkar et al., Investigation of a complex nocturnal flow in Owens valley, California using coherent Doppler lidar, 2012, Boundary Layer Meteorology.

[5] Krishnamurthy et al., 2012, Wind farm characterization using scanning Doppler lidar, 2013, Wind Energy.

[6] Collier et al., Dual-Doppler lidar measurements for improving dispersion models, 2005, B AM METEOROL SOC, 86, pp. 825 .

[7] Seig et al., Scanning Doppler lidar for reduced uncertainty, 2014, AWEA Wind Resource Assessment conference. 